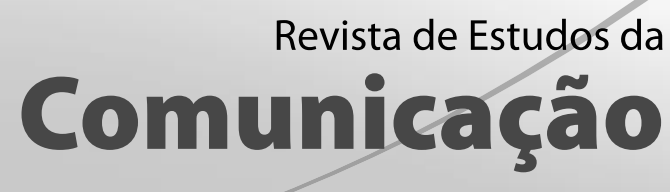

doi: 10.037/comunicaca0.16.039.A006

ISSN 1518-9775

Licenciado sob uma Licença Creative Commons

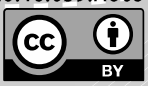

\title{
O universo narrativo de Latitudes: primeiros apontamentos
}

The narrative universe of Latitudes: first approach

\section{Maria Cristina Palma Mungioli ${ }^{[a]}$,}

\section{Tomaz Affonso Penner ${ }^{[b]}$}

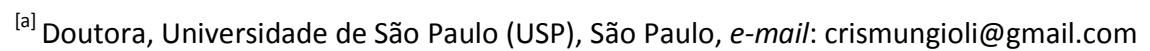

${ }^{[b]}$ Mestrando, Universidade de São Paulo (USP), São Paulo, e-mail: tomazpenner@gmail.com 


\section{Resumo}

Por meio do estudo das estratégias de transmidiação (MASSAROLO, 2011 e 2013), o trabaIho busca categorizar (FECHINE, 2013) as relações em múltiplas mídias estabelecidas pela ficção Latitudes. Veiculado pelo YouTube, televisão e cinema, Latitudes foi concebido desde o princípio como um projeto transmídia. Percebe-se o estabelecimento da websérie como nave-mãe (JENKINS, 2006) que centraliza o eixo narrativo da trama e a atuação da televisão e cinema como plataformas de complementação de conteúdo, em uma lógica contrária à constituída tradicionalmente, principalmente na produção ficcional brasileira. Percebe-se também que, quando a transmidiação de ficções ocorre em mais de duas plataformas, é preciso analisar detalhadamente cada uma das relações estabelecidas; colocar em prática categorizações revelou a complexidade das estratégias e dos conteúdos de transmidiação e a impossibilidade de generalizar as relações transmidiáticas estabelecidas em uma produção ficcional.

Palavras-chave: Transmidiação. Latitudes. Narrativa Ficcional.

\section{Abstract}

Through the study of transmidiation strategies (MASSAROLO, 2011 and 2013), this research presents a categorization (FECHINE, 2013) of the relationships in multiple media established by the audiovisual fiction Latitudes. Conveyed by YouTube, television and cinema, Latitudes was conceived from the beginning as a transmedia project. We can observe the establishment of the webserie as the mothership (JENKINS, 2006) that centralizes the narrative, and the television and cinema as complementation content platforms, in a different logical that traditionally constitutes brazilian fictional productions. It becomes clear, as well, that when transmidiatic fictions appear in more than two platforms, it is necessary to analyze in detail each one of the established relationships; put into practice categorizations revealed the complexity of the strategies and transmidiatic contents and the impossibility of generalizing transmedia relations established in a fictional production.

Keywords: Transmidiation. Latitudes. Fictional narrative.

\section{Introdução}

O presente trabalho se caracteriza como uma primeira aproximação em relação ao Projeto Transmídia Latitudes, considerando alguns de seus elementos narrativos como integrantes de um conjunto de estratégias adotadas visando à constituição de um universo narrativo que se desdobra em diversas plataformas (televisão, internet e cinema) e diferentes formatos (série de televisão, websérie, 
filme). Para isso, consideramos com Bakhtin (2003, p. 177) que, na materialidade da obra estética, apresentam-se tensões entre os três elementos que a compõem: "o conteúdo, o material, a forma". O estudo aqui empreendido também considera as contribuições de Jenkins $(2008,2013)$ e Fechine (2013). Destacam-se entre os objetivos do artigo: (1) identificar qual plataforma se apresenta como o locus da nave-mãe da narrativa (JENKINS, 2008) e (2) identificar as estratégias transmídia adotadas na produção.

\section{Cultura da convergência e narrativas transmídia}

Intrinsecamente relacionada às transformações tecnológicas que impactaram os meios de comunicação nas últimas décadas, a cultura da convergência (JENKINS, 2008) se apresenta como um fenômeno complexo que articula indústrias, sistemas e modos de produção, conteúdos, gêneros, formatos, uma vez que:

A convergência não depende de qualquer mecanismo de distribuição específico. Em vez disso, a convergência representa uma mudança de paradigma - um deslocamento de conteúdo midiático específico em direção a um conteúdo que flui por vários canais, em direção a uma elevada interdependência de sistemas de comunicação, em direção a múltiplos modos de acesso a conteúdos midiáticos e em direção a relações cada vez mais complexas entre a mídia corporativa, de cima para baixo, e a cultura participativa, de baixo para cima. (JENKINS, 2008, p. 310).

Ainda nas palavras de Jenkins (2008, p. 311), vivemos "um momento de transição, no qual antigas regras estão abertas a mudanças" e dependem de uma complexa negociação que envolve tensões entre modelos de produção, distribuição e circulação de conteúdos tradicionalmente instituídos e a sua reconfiguração a partir de um cenário em que "as três formas de comunicação (interpessoal, comunicação de massa, e mass self-communication ${ }^{1}$ ) coexistem, interagem e que tanto se complementam mutuamente quanto se substituem." (CASTELLS, 2009, p. 55).

É nesse cenário que emerge a narrativa transmídia (JENKINS, 2008), que, conforme resumem Lopes e Mungioli:

Castells (2009, p. 55) conceitua mass self-communication como "uma nova forma de comunicação que emergiu, caracterizada pela capacidade de mandar mensagens de muitos para muitos, em tempo real ou em determinado tempo, e com a possibilidade de comunicação ponto a ponto, narrowcasting (comunicação segmentada) ou broadcasting, dependendo da proposta ou das características de uma determinada prática de comunicação." 
Trata-se da criação de um universo ficcional cujo conteúdo pode ser expandido tanto em termos de personagens quanto em termos de desenvolvimento narrativo. Não se trata de uma repetição da história, mas de um desdobramento da história principal que ganha elementos diferentes (personagens, ambientes, conflitos) que tiram proveito das qualidades que cada um dos meios pode oferecer para o desenvolvimento da narrativa. (LOPES; MUNGIOLI, 2009, p. 253).

Nesse contexto, a construção de universos narrativos começa a se delinear com base nas potencialidades específicas de um meio, "de modo a garantir o seu consumo autônomo [do conteúdo]" (SCOLARI, 2013, p. 24). Nesse sentido, destaca Jenkins:

cada vez mais, as narrativas estão se tornando a arte da construção de universos, à medida que os artistas criam ambientes atraentes que não podem ser completamente explorados ou esgotados em uma única obra, ou mesmo em uma única mídia. O universo é maior do que o filme, maior, até, do que a franquia -já que as especulações e elaborações dos fãs também expandem o universo em várias direções. (JENKINS, 2008, p. 158).

Entretanto, o próprio autor afirma, em entrevista concedida a Scolari (2013), que a narrativa transmídia não pode ser compreendida apenas como resultado do uso de diferentes mídias para contar uma história com a qual interagem, de diversas maneiras, os fãs. Ao contrário, para ele, para que a narrativa transmídia se constitua como tal, é:

essencial que na obra exista uma intertextualidade radical -ou seja, que as diferentes partes estejam conectadas entre si de algum modo -, o qual tem a ver com o conceito de multimodalidade e o fato de ser planejado para uma cultura em rede. Todas essas coisas vêm juntas. (JENKINS apud SCOLARI, 2013, p. 34).

Interessa, sobretudo, aos objetivos deste trabalho observar se alguns elementos de "intertextualidade radical" podem ser encontrados na ficção Latitudes enquanto projeto transmídia que envolveu conteúdo especificamente produzido para internet, televisão e cinema. Nesse sentido, procuramos analisar alguns mecanismos que, a nosso ver, constituem-se como elementos-chave para a construção de uma narrativa ficcional transmídia. Por outro lado, cabe observar que, para Scolari (2013, p. 25), outro termo que faz parte da mesma "galáxia semântica" de narrativa transmídia é cross media, que designa a disseminação de conteúdo entre plataformas. Segundo Boumans (2005), trata-se de um termo de difícil definição, pois seu significado se altera de acordo com a área na qual é usado: 
Para impressão e publicação, normalmente significa o uso de várias mídias para facilitar o acesso ao conteúdo, como colocar um CD anexo a um livro para permitir a busca textual. Em uma produção na internet, cross media se refere a alcançar a eficiência em mais de uma plataforma técnica ou tornar o processo "escalável" para várias pessoas ou telas. Para o Marketing, o termo é confundido com "cross-channel", o uso de vários canais de distribuição (...). Além dessas, cross media penetrou também o e-learning e o turismo. (BOUMANS, 2005, p. 127).

O termo, então, refere-se, preferencialmente, a ações planejadas pelo polo da produção para inserir conteúdos em diversas mídias, objetivando, entre outras coisas, uma distribuição integrada de seus produtos. Assim, o princípio que regeria esse procedimento seria o da complementaridade de conteúdos criada a partir de um polo produtor, indicando, talvez, sua principal diferença em relação a transmedia storytelling, tal qual a define Jenkins (2008, p. 47), que se caracteriza pela participação ativa de consumidores em comunidades de conhecimento. Vale frisar que, para os propósitos de nosso trabalho, utilizaremos o termo narrativa transmídia, uma vez que nosso objetivo é analisar os elementos de construção da narrativa em cada um dos formatos, em suas respectivas plataformas, a fim de delinear os procedimentos narrativos empregados.

\section{A narrativa transmídia de Latitudes}

Conforme enunciamos na introdução deste artigo, consideramos, com base nas discussões de Bakhtin (2003), que a constituição da obra estética encerra tensões entre os três elementos que a compõem: o conteúdo, o material e a forma. Tais tensões podem ser observadas em diferentes produtos culturais, mas, no caso específico das narrativas transmídia, é preciso estar atento para o fato de que o trânsito de um conteúdo narrativo de um meio para outro possui consequências para a narrativa em si, uma vez que:

Um núcleo de significado pode viajar através de diferentes plataformas, mas o seu potencial narrativo será complementado, atualizado de forma diferente conforme é transmitido em um novo meio. Quando se trata de possibilidades narrativas, os diferentes meios não são igualmente dotados: alguns são melhores contadores de histórias, outros sofrem de deficiências graves. O conceito de narrativa oferece denominadores comuns que permitem uma melhor apreensão dos pontos fortes e limitações do poder de representação dos meios de comunicação. (RYAN, 2005, p. 2). 
Buscando entender como os diversos meios se configuram e se complementam na construção do universo narrativo de Latitudes, procuramos estudar não apenas o conteúdo narrativo em si, mas também as estratégias de sua exibição nas diferentes plataformas.

\section{Estratégias de transmidiação em Latitudes: uma história em três plataformas}

Latidudes é uma narrativa apresentada em multiplataformas, cuja trama conta os encontros e desencontros do casal José (Daniel de Oliveira) e Olívia (Alice Braga) em diversas cidades do mundo. A trama foi produzida em três formatos diferentes: websérie, seriado de televisão e filme de longa-metragem, para exibição na internet, televisão paga e cinema, respectivamente. São oito episódios para a televisão e oito para o YouTube, cada um ambientado em uma cidade diferente do mundo (Paris, Londres, Veneza, José Ignácio, São Paulo, Porto, Buenos Aires e Istambul). São expostas as dificuldades de superação da efemeridade que os protagonistas - ele, um fotógrafo renomado e ela, uma famosa editora de moda estabelecem em suas relações, por conta das constantes viagens a trabalho. No cinema, há uma compactação dos episódios em um filme, cujas sequências são dividias linearmente na mesma ordem dos episódios no seriado de televisão e na websérie de Latitudes.

A mesma história é apresentada de maneiras diferentes em cada uma das plataformas envolvidas, em uma concepção transmídia elaborada desde o momento da produção, denotando uma ação estratégica articulada entre mídias, configurando-se como uma narrativa transmídia (JENKINS, 2008; SCOLARI, 2013; FECHINE, 2013).

Os oito episódios on-line, com doze a dezessete minutos de duração, foram disponibilizados cada um em uma segunda-feira, a partir da estreia, dia 28 de agosto de 2013. Na televisão, os oito episódios, com vinte a vinte e cinco minutos, foram exibidos pela $\mathrm{TNT}^{2}$ às quartas, estreando dia 02 de setembro de 2013. A versão para o cinema, com uma hora e vinte minutos de duração, estreou dia 28 de fevereiro de 2014.

Dirigida por Felipe Braga, Latitudes é apresentada desde sua concepção como uma narrativa transmídia. É possível observar que os episódios no canal do YouTube ${ }^{3}$ contam uma história que começa, se desenvolve e acaba nessa plataforma, sem necessidade de complementações para que se entenda integralmente

Turner Network Television, canal de televisão por assinatura especializado em filmes e séries, criado, em 1988, pelo magnata da mídia Ted Turner.

Canal no YouTube: <http://youtube.com/user/Latitudesfilme>. 
a narrativa. É interessante também observar que essa plataforma foi a primeira a exibir a ficção, seguida pela TV e, por último, pelo cinema. No site é possível observar uma narrativa puramente diegética, que se passa exclusivamente em tempo e espaço correspondentes à trama ficcional. Essa descrição é importante, pois é preciso:

Entender não somente o que é narrado, mas a forma como a história é contada, caracteriza a estética da repetição como a experiência de reassistir episódios ou partes deles pelos mais diversos motivos, desde análises dos momentos mais significativos, passando pelas questões emocionais (MASSAROLO, 2013, p. 339).

Inicialmente disponibilizados no canal do YouTube, os episódios televisionados contêm a mesma trama diegética disponibilizada on-line, acrescida aos extras da produção. Além disso, os realizadores esperam uma fidelização do público a partir das duas primeiras plataformas citadas, para que a audiência compareça também às salas de cinema, a fim de reassistir à narrativa com nova edição e trilha sonora. Por ter sido veiculado inicialmente pela internet, Latitudes seria uma produção que já chega aos cinemas com um público formado ${ }^{4}$. Percebe-se, portanto, a estética da repetição (MASSAROLO, 2013) como estratégia de narrar transmidiaticamente a obra Latitudes.

Além disso, mais uma estratégia de transmidiação identificada na obra é a inclusão de cenas deletadas (JENKINS, 2013) na plataforma televisiva. Jenkins (2013) diferencia as cenas deletadas das cenas faltantes (missing scenes). De acordo com o autor, enquanto as cenas faltantes se referem a partes da história deixadas com lacunas sem a intenção dos realizadores da obra, as cenas deletadas referem-se às partes que os produtores retiraram intencionalmente da narrativa. Ao observar a inclusão de novos conteúdos na televisão (que não estão disponíveis na websérie), percebe-se que se trata da inserção de cenas deletadas da narrativa para o YouTube, em uma estratégia da produção para levar o público à busca por novos conteúdos na plataforma televisiva, diegéticos ou não.

Ambos (cenas deletadas e cenas faltantes) podem representar contribuições criativas para a nossa compreensão do trabalho, mas eles têm status diferente, pois nossa cultura tende a valorizar o autor original sobre seus leitores (JENKINS, 2013, p. 16).

GENESTRETI, G. Follha de S Paulo, Ilustrada, 05.03.14.

Disponivel em: <http://www1.folha.uol.com.br/fsp/ilustrada/154946-em-todas-as-telas.shtml>. Acesso em: 30.03.2014. 
Percebe-se, portanto, o estímulo à migração da audiência entre várias plataformas, com a intenção de fornecer ao espectador experiências narrativas e de interpretação exclusivas de cada um dos veículos de distribuição da produção ficcional. Aí se identifica mais uma estratégia da produção, que busca cativar o público da internet para que este busque novos conteúdos na televisão e compareça às salas de cinema, mesmo já conhecendo a história.

Nesse ponto, a websérie Latitudes no YouTube se destaca como núcleo central da diegese, além de plataforma original de divulgação da fiç̧ão. A partir da descrição dos vídeos no site, a audiência é chamada para conferir a produção na TV, com conteúdos adicionados. Ainda que, no decorrer das semanas, os episódios avançassem concomitantemente no canal TNT e no YouTube, eles eram lançados primeiro na plataforma digital (às quartas-feiras), para depois serem exibidos na televisão (nas segundas-feiras seguintes). Desse modo, a internet se estabelecia como o primeiro contato com a produção, como o veículo original a partir do qual a audiência parte para a busca de novos conteúdos. O cinema vem por último, com a expectativa de o envolvimento do público já ter sido estabelecido anteriormente.

\section{As estruturas narrativas de transmidiação em Latitudes}

O que diferencia os episódios on-line dos televisionados é, precisamente, que, na televisão, eles fogem do universo puramente diegético e são reveladas particularidades da produção. A narrativa ficcional permanece a mesma, mas surgem complementações que explicam a produção da trama e apresentam detalhes comportamentais das personagens. Em vários momentos da narrativa televisiva, por exemplo, o diretor Felipe Braga aparece lendo partes do roteiro enquanto a cena acontece e explicando por que a trama se desenvolve dessa maneira. A atriz Alice Braga (Olívia), no meio de um ensaio da cena apresentada no terceiro episódio (3 Destino - Veneza) na televisão, aparece descrevendo os desejos e anseios de controle característicos de sua personagem. Essas estratégias funcionam como uma forma de desconstrução da narrativa em sua dimensão discursiva (quebra de temporalidade, espacialidade, instância enunciativa) ao mesmo tempo em que estabelece um novo discurso em que se mesclam as falas (confissões) das personagens e a ação do diretor (por trás das câmeras), "denunciando", dessa forma, a criação ficcional.

No cinema, a estrutura narrativa ganha novos cortes e trilha sonora, mas a história se desenvolve basicamente da mesma maneira que foi disponibilizada na internet. Por ter sido a última plataforma, o cinema pode ser encarado como uma oportunidade de assistir na telona uma história que já cativou o público pela internet e televisão. 
Em uma primeira aproximação, pode-se dizer que a televisão possui um papel secundário, ou seja, funciona como plataforma satélite da plataforma web (YouTube), cumprindo o papel de propagar ${ }^{5}$ a narrativa exibida no YouTube. Fica clara, portanto, a opção estratégica de conferir a cada uma das plataformas um papel na constituição do universo narrativo de Latitudes. Cabe salientar que o conteúdo extra oferecido na televisão não expande o universo diegético da narrativa, ao contrário, age no sentido de apresentá-la como uma narrativa ficcional e revela detalhes de sua produção, elucidando desde técnicas de iluminação e enquadramento até o ponto em que os sentimentos sugeridos pelas personagens na trama são descritos detalhadamente pelos atores e diretor. Esse conjunto discursivo complementar caracteriza-se como uma espécie de making of da produção, apresentado de maneira parcelada, em episódios semanais, nos quais se mesclam a narrativa ficcional e a narrativa sobre a ficção, constituindo um enunciado sobre o enunciado (BAKHTIN; VOLOCHINOV, 2002). Ou seja, um discurso dentro do discurso.

O que é interessante notar nessa situação é a inversão que se observa em relação ao papel da televisão, tradicionalmente vista como a mídia mais importante em termos de audiência, que passa a ter um papel secundário em relação ao conteúdo disponibilizado na internet. É a websérie que concentra a narrativa diegética em sua totalidade e conta com a televisão para mostrar os extras da produção. Sem dúvida, é uma mudança que merece nota, para se entender de que maneira o YouTube vem se inserindo na cultura da convergência e na lógica do entretenimento audiovisual.

(...) nos interrogamos se o YouTube introduziu algo de novo no contexto de uma história maior, que é a das mídias e linguagens audiovisuais. Então nos perguntaremos: que novidades foram trazidas por essa história e esse contrato de fundação para a história da cultura e midiatização audiovisual, que é o contexto em que, a partir de nossa perspectiva, devemos analisá-lo? Isto é, em que medida o YouTube nasceu e se constituiu como um projeto separado do cinema e da televisão ou constitui, por outro lado, uma continuidade destes dois grandes meios de comunicação que o antecederam? Estas são perguntas que nos forçam a rever a situação atual como uma mídia e, por isso mesmo, a discutir a tese de Amanda Lotz (2007), que sustenta que no YouTube há, na post-network era, que é a mesma que estamos vivendo agora, a partir das produções dos usuários, manifestações de uma nova fase na história da televisão (CARLÓN, 2013, p. 109).

Abaixo será apresentado o quadro de Fechine (2013) que categoriza as relações de transmidiação estabelecidas em Latitudes. 
Desse modo, percebe-se o YouTube e a disponibilização on-line de conteúdos como mais que meras complementações ou complexificações das narrativas televisuais ou cinematográficas. Ele mesmo é utilizado (e foi, no caso de Latitudes), como a plataforma original de lançamento de um projeto transmídia, que comporta a narrativa central e conta com os outros meios para retomá-la e disponibilizar informações extras. Fato esse reforçado por Felipe Braga, diretor da obra: "Nós queríamos estrear on-line justamente porque sempre ocorre o oposto: a internet é normalmente encarada como plataforma para se jogar o que tem de menos valor, os extras"

Do ponto de vista da estrutura narrativa e discursiva da versão de Latitudes para o cinema, podemos dizer que ela se caracteriza basicamente pela concentração de todos os episódios reeditados, com ligeiros cortes e alterações de montagem. A principal mudança estrutural do filme em relação às narrativas seriadas de Latitudes é o preenchimento de diálogos com imagens, quando eles originalmente eram encenados pelas personagens. No 2을 Destino - Londres, por exemplo, em uma sequência que originalmente mostrava um plano de José e Olívia dialogando, as cenas das personagens conversando sobre seu encontro no 10 Destino - Paris foram cobertas por imagens do dia de Olívia em Paris, que não existem na trama seriada - nem no YouTube, nem na televisão.

É possível definir, portanto, a websérie Latitudes como a nave-mãe (JENKINS, 2008) da produção ficcional. Ou seja, é a narrativa que concentra a trama central, a partir da qual se espera que a audiência parta para novas plataformas em busca de informações adicionais.

Pense, por exemplo, naquilo que as extensões transmidiáticas fazem. Elas oferecem mais informação e a oportunidade de explorar mais plenamente os mundos ficcionais. Permitem o engajamento com histórias de pano de fundo ou realçam o impacto a longo prazo dos eventos narrativos. Ou ainda redirecionam o foco em torno das perspectivas de personagens secundários ou periféricos, retornando à "nave-mãe" com um novo quadro de referência. Neste momento, estamos ainda mapeando o território, identificando dispositivos formais e modos narrativos que funcionam num ambiente transmidiático, esbarrando ocasionalmente em exemplos que contêm grande força emocional ou complexidade cognitiva. Existem pessoas monitorando os experimentos e refinando a arte. Entre elas estão os artistas que vão levar as transmídias ao próximo nível. $\mathrm{E}$ também os consumidores, que vão acompanhar esses artistas e ajudá-los a rea-

GENESTRETI, G. Folha de S. Paulo, llustrada, 05.03.14.

Disponivel em: <http://www1.folha.uol.com.br/ilustrada/2014/03/1420884-latitudes-e-bom-demerchandising-mas-nao-atraiu-investidores.shtml>. Acesso em: 30.03.2014.

Rev. Estud. Comun., Curitiba, v. 16, n. 39, p. 81-96, jan./abr. 2015 
lizar plenamente o seu potencial (JENKINS apud NAVARRO, 2010, p. 24).

O conteúdo exibido pela televisão é, desse modo, um meio de estreitar as relações do público com as etapas de produção de Latitudes e de reapresentar os personagens com mais profundidade, de maneira que o espectador retorne à narrativa ficcional com novas perspectivas interpretativas. É, portanto, uma maneira de redirecionar indivíduos com novos e complexificados olhares à história desenvolvida anteriormente na nave-mãe. Essa renovação do olhar da audiência ocorreu por meio de comentários do diretor Felipe Braga e dos atores Alice Braga e Daniel de Oliveira, que são intercalados com a trama ficcional no decorrer dos episódios televisionados.

O longa-metragem, embora apresentasse uma montagem diferente daquelas apresentadas nas duas outras plataformas, serviu como uma forma de manutenção do conteúdo da narrativa transmídia. A principal diferença entre o filme e os episódios disponibilizados no YouTube se refere à construção narrativa e discursiva das cenas em que surgem as memórias das personagens, que, nas versões seriadas de Latitudes, eram apenas narradas. No cinema, elas foram cobertas com imagens, permitindo que o público "visse" essas memórias em pelo menos dois momentos: 1) em Londres, lembrando o dia que poderiam ter passado juntos em Paris; e 2) durante a viagem de Olívia do Porto para Buenos Aires, na qual ela aparece sentada no avião com o celular nas mãos. Ou seja, trata-se de conteúdos ficcionais inéditos na história narrada anteriormente em outras plataformas que, no entanto, não expandem o universo ficcional (JENKINS, 2008).

\section{Operações e categorizações de transmidiação em Latitudes}

Fechine (2013) oferece categorias para estabelecer as operações de transmidiação em determinada produção dramatúrgica.

Quadro 1: Estratégias e conteúdos transmídia.

(Continua)

\begin{tabular}{lll} 
Estratégias & \multicolumn{1}{c}{ Conteúdos } \\
& & \\
& Conteúdos reformatados & Antecipação \\
\cline { 2 - 3 } Propagação & Recuperação \\
\cline { 2 - 3 } & \multirow{2}{*}{ Conteúdos informativos } & Remixagem \\
\cline { 2 - 2 } & & Contextuais \\
\hline
\end{tabular}


Quadro 1: Estratégias e conteúdos transmídia.

\begin{tabular}{lll} 
Estratégias & \multicolumn{1}{c}{ (Conclusão) } \\
& $\begin{array}{ll}\text { Conteúdos de extensão } \\
\text { textual }\end{array}$ & Extensões narrativas \\
\cline { 2 - 3 } Expansão & Conteúdos de extensão lúdica & Extensões vivenciais \\
\cline { 3 - 3 } & & Extensões de marca \\
\hline
\end{tabular}

F onte: FECHINE, 2013, p. 37.

É importante fazer uma breve explicação das categorias para que sejam definidas quais operações de transmidiação se estabelecem na obra Latitudes. A princípio, Fechine categoriza dois tipos de estratégias: propagação e expansão. Por propagação se entende a recuperação e repercussão dos conteúdos ficcionais em várias plataformas, em um circuito retroativo de interesse. A expansão, por outro lado, se refere ao aumento dos universos narrativos para além da plataforma principal. Cria histórias interdependentes, mas dotadas de sentido se consideradas isoladamente. Quanto aos conteúdos transmídia na esfera da Propagação, podem ser classificados como 1) Reformatados (adaptam para outras plataformas conteúdos que já foram ofertados na plataforma principal - não oferecem novas informações, mas variações do conteúdo original); e 2) Informativos (por meio de outras plataformas, oferecem informações associadas ao texto de referência que não interferem diretamente na diegese - ou seja, não são ficcionais, mas ajudam a compreender a ficção). Na esfera da Expansão, há outras duas categorias possíveis para os conteúdos: 1) de Extensão textual (responsáveis por desdobramentos diegéticos, estendem o texto de referência a partir de seus núcleos, como caracterização de personagens, lugares e ambientes); e 2) de Extensão lúdica (referem-se a jogos para interação com os usuários, em busca de conexões entre a unidade narrativa e o aspecto lúdico).

Dentro da estratégia de Propagação, os Conteúdos reformatados se dividem em três categorias: 1) Antecipação (despertam interesse nos consumidores sobre a narrativa principal, adiantando em outras mídias o que será exibido); 2) Recuperação (possibilitam que os consumidores revejam cenas, por meio da reexibição da programação original em outras plataformas); e 3) Remixagem (são resultado da apropriação do conteúdo original em outro contexto - reeditado, com imagens manipuladas - , que permite a ressignificação de sequências já exibidas).

Entre os Conteúdos informativos, existem mais duas divisões: 1) Contextuais (oferecem informações "reais" sobre o contexto da diegese, como fatos históricos que ajudam no entendimento da trama); e 2) Promocionais (proporcionam conhecimento sobre o fazer-se da narrativa, com informações sobre os profissionais envolvidos e a realização da obra, estabelecendo uma metanarrativa). 
Na esfera da Expansão, entre os Conteúdos de extensão textual, existem as: 1) Extensões narrativas (novas narrativas, desenvolvidas em outros meios, a partir de recuos ou avanços da narrativa principal); e 2) Extensões diegéticas (oferecem novos conteúdos narrativos ligados diretamente à diegese - são diferenciadas das extensões narrativas por não interferirem no encadeamento das ações na trama principal. Tratam-se, portanto, de diários, álbuns de fotografias e outros documentos e artefatos apresentados ao público que aumentam a impressão de realidade sobre a narrativa).

Por fim, aparecem as categorias dos Conteúdos de extensão lúdica, a saber: 1) Extensões vivenciais (exigem o envolvimento ativo do consumidor em atividades propostas pelos produtores, como games, quizzes e concursos - relacionados à narrativa central e disponíveis em outras plataformas); e 2) Extensões de marca (promove a narrativa do mundo simbólico para o material, trazendo o consumidor para "dentro" da diegese, por meio de conteúdos promocionais, como protetores de tela, roupas e toques para celular).

Por meio das estratégias de produção anteriormente elucidadas nesse trabalho, é possível categorizar Latitudes como uma obra que desenvolve a Estratégia Transmídia de Propagação, com um conteúdo repercutindo ou reverberando o outro, atiçando os consumidores a retomarem a trama em várias plataformas. Quanto às ações transmídia, elas flutuam de acordo com a plataforma considerada. A partir de agora, serão consideradas duas operações de transmidiação diferentes, ambas categorizadas a partir do que se estabeleceu como a nave-mãe da ficção Latitudes: a websérie disponibilizada no YouTube.

\section{a) Do YouTube para a televisão}

Na televisão observa-se a predominância de Conteúdos informativos, por conta da inserção de informações "de fora da trama" que ajudam a compreendê-la e discriminá-la enquanto diegese.

[Os Conteúdos informativos] exploram aspectos pertinentes à narrativa sem interferirem, no entanto, na "realidade" interna à trama (sem implicação ou participação nas ações). Colaboram para construção de conhecimento "enciclopédico" em torno da diegese e/ou do processo de produção do programa (FECHINE, 2013, p. 41).

É precisamente o que acontece quando a produção original do YouTube é veiculada na televisão. A trama permanece a mesma, mas os episódios ganham comentários do diretor e dos atores, além de explicações sobre ângulos de câmera, iluminação e sentimentos das personagens, que são intercalados com o desenvol- 
vimento da fiç̧ão. Esses "extras" evidenciam, portanto, a encenação, aumentando o grau de compreensão da etapa produtiva que está "fora" do universo ficcional.

Entre os Conteúdos informativos na relação de transmidiação YouTube - Televisão, predominam os Promocionais. "São informações de caráter marcadamente extratextual sobre os profissionais envolvidos e os processos de realização" (FECHINE, 2013, p. 43). É, precisamente, por meio dessas ações que os produtores buscam redefinir os olhares da audiência para que retornem à fiç̧ão com novas informações a respeito dos caminhos que levaram à construção e desenvolvimento da trama. É possível destacar as estratégias e conteúdos transmídia da ficção Latitudes em sua flutuação da internet para a televisão da seguinte maneira, a partir do quadro proposto por Fechine: Estratégia de Propagação, com Conteúdos informativos promocionais.

b) Do YouTube para o cinema

No cinema, verifica-se a predominância de Conteúdos reformatados, que não oferecem novas informações, mas variações da narrativa principal (FECHINE, 2013). É, precisamente, o que ocorre nos cinemas, plataforma cuja principal mudança é a montagem do produto final. Basicamente, os episódios da websérie Latitudes, ao virarem o filme Latitudes, tiveram: 1) algumas cenas cortadas e outras reordenadas (a maneira como o casal José e Olívia se conhece, por exemplo, que é esclarecida no 1 o Destino - Paris, é a última cena do filme); 2) trilha sonora ligeiramente modificada para tirar a ideia de fim de cada episódio; e 3) algumas imagens inéditas, inseridas para cobrir os diálogos das personagens.

Entre os Conteúdos reformatados predominantes na relação de transmidiação YouTube - Cinema, destaca-se a Recuperação. Os conteúdos de recuperação permitem ao público ter acesso à mesma trama estabelecida a partir da narrativa central, mas reformatada para a realidade da sua plataforma. É precisamente o caso do filme Latitudes; ele é quase uma montagem dos episódios disponibilizados pelo YouTube, com pequenas diferenças de edição, que o adaptam à realidade cinematográfica. É possível destacar as estratégias e conteúdos transmídia da ficção Latitudes em sua flutuação da internet para o cinema da seguinte maneira, a partir do quadro proposto por Fechine: Estratégia de Propagação, com Conteúdos reformatados de recuperação.

\section{Considerações finais}

Uma grande discussão levantada a partir dos resultados deste estudo é a localização da nave-mãe em uma plataforma on-line (YouTube). Normalmente, em 
relações de transmidiação que envolvem internet e televisão ou internet e cinema, a narrativa central se concentra nos filmes ou nas produções de ficção televisiva, de modo que a internet atua como satélite para repercutir conteúdos que complementam as histórias contidas em outras mídias. Tanto é verdade que as próprias categorias desenvolvidas por Fechine e utilizadas nesse trabalho consideravam originalmente as telenovelas, sempre, como o eixo central a partir do qual a narrativa se espalha (para a internet).

A própria pesquisadora, entretanto, abre a possibilidade para novas dinâmicas de aplicação dessas categorias, dando "permissão" para a análise feita nesse trabalho. Em Latitudes, observa-se um reconhecimento do potencial do YouTube para abrigar o eixo central da ficção e espalhar a narrativa e conteúdos relacionados a ela nas demais plataformas. É um novo modelo de produção e de negócio audiovisual ficcional que merece nota e aprofundamento reflexivo.

Esse potencial dinâmico das categorias tem mais um desdobramento interessante: possibilita que os processos de transmidiação em uma única obra sejam pluralizados e classificados individualmente. Quando se fala em transmidiação de ficções em mais de duas plataformas, é preciso analisar, detalhada e particularmente, cada uma das relações estabelecidas. A estratégia metodológica adotada para este trabalho foi analisar as relações sempre a partir do que foi estabelecido como nave-mãe da narrativa, uma decisão tomada durante o desenvolvimento da pesquisa, quando colocar em prática as categorizações revelou a complexidade das estratégias e dos conteúdos de transmidiação. Foi preciso classificar distintamente as relações estabelecidas a partir da transmidiação entre YouTube e televisão e entre YouTube e cinema, ao invés de reduzir tudo à transmidiação na obra Latitudes. Essa mesma produção, inclusive, estabelece novas estratégias e tipos de conteúdos transmidiáticos em trailers, redes sociais e sites, que não foram contemplados nesse trabalho, mas representam um rico campo de estudos para o futuro.

\section{Referências}

BAKHTIN, M.; VOLOCHINOV, V. N. Marxismo e filosofia da linguagem. São Paulo: Hucitec, 2002.

Estética da criação verbal. São Paulo: Martins Fontes, 2003.

BOUMANS, Jack. Cross-media on the advance. In: BRUCK, P. A. (et al.) (ed.).

E-Content: technologies and perspectives for the European market. Berlin-Heildelberg: Springer, 2005, p. 127-141. 
CARLÓN, M. Contrato de fundação, poder e midiatizaçãoo: notícias do front sobre a invasão do YouTube, ocupação dos Bárbaros. MATRIZes - Revista do Programa de Pós-Graduação em Ciências da Comunicação da Universidade de São. Paulo. São Paulo: ECA/USP, v. 01, cap. 5, p. 107-126, 2013.

CASTELLS, M. Communication power. New York: Oxford University Press, 2009.

FECHINE, Y. Como pensar os conteúdos transmídias na teledramaturgia brasileira? Uma proposta de abordagem a partir das telenovelas da Globo. In: LOPES, M. I. V. (Org.). Estratégias de transmidiação na ficção televisiva brasileira. Porto Alegre: Sulina, 2013. cap. 1, v. 3, p. 19-60.

JENKINS, H. Cultura da convergência. São Paulo: Aleph, 2008. - Lendo criticamente e lendo criativamente. MATRIZes - Revista do Programa de Pós-Graduação em Ciências da Comunicação da Universidade de São Paulo. São Paulo: ECA/USP, v. 02, cap. 1, p. 11-24, 2012.

MASSAROLO, J. Narrativas transmídias geolocalizadas. In: Seminário Internacional da Comunicação PPGCOM, 11., 2011. Porto Alegre. Resumos... Porto Alegre: EdiPUCRS, 2011, ps. 171-172.

. Storytelling transmídia: Narrativa para multiplataformas. Tríade. Sorocaba, n. 02, 335-347, 2013.

NAVARRO, V. Sites of Convergence: an interview with Henry Jenkins. Revista Contracampo. Niterói, n. 21, 02-26, 2010.

RYAN, M. L. On the theoretical foundations of transmedial narratology. In: MEISTER, J. C. (ed.). Narratology beyond literary criticism: mediality, disciplinarity. Berlin: Walter de Gruyter, 2005.

SCOLARI, C. A. Narrativas trasmedia: cuando todos los medios cuentam. Barcelona: Deusto, 2013.

Recebido: $11 / 11 / 2014$

Received: $11 / 11 / 2014$

Aprovado: 16/03/2015

Approved: 16/03/2015 